\title{
IMPLICAÇÓES SURGIDAS NO USO DE TECNOLOGIAS DIGITAIS NO DESENVOLVIMENTO DE ATIVIDADES DE MODELAGEM MATEMÁTICA
}

\author{
Rhômulo Oliveira Menezes* \\ Roberta Modesto Braga* \\ Adilson Oliveira do Espírito Santo ${ }^{* * *}$
}

\section{Resumo}

O objetivo deste artigo é investigar implicaçôes surgidas no uso da planilha eletrônica Excel para o desenvolvimento de uma atividade de Modelagem Matemática. O método de estudo foi o qualitativo e os dados foram coletados no Laboratório Experimental de Modelagem Matemática, do Campus Universitário de Castanhal, da Universidade Federal do Pará (LEMM/CUNCAST/UFPA). Os resultados indicam que o uso de tecnologias digitais repercute na tomada de decisóes dos alunos, impactando o desenvolvimento das próximas etapas do processo de Modelagem Matemática.

Palavras-chave: Implicações. Tecnologias digitais. Atividades de Modelagem Matemática.

\section{INTRODUÇÁO}

Nas últimas décadas, a disseminação da informática em práticas do cotidiano, além de promover mudanças na forma de escrever, pensar, ver, ouvir, provocou alteraçóes na forma como se ensina e no acesso ao conhecimento. Essas mudanças também foram sentidas no desenvolvimento de atividades de Modelagem Matemática, ensejando pesquisas - Araújo (2002), Malheiros (2004), Diniz (2007), entre outras - preocupadas em investigar fenômenos oriundos do uso de tecnologias digitais em atividades de Modelagem Matemática.

Assim, neste artigo, pretendemos investigar implicaçóes surgidas com o uso da planilha eletrônica Excel no desenvolvimento de uma atividade de Modelagem Matemática. Este artigo representa parte dos resultados obtidos com a pesquisa de dissertação de mestrado do primeiro autor, na qual foram utilizados dados gerados por alunos da graduação do curso de Licenciatura em Matemática no LEMM/CUNCAST/UFPA. As análises apresentadas neste trabalho estão embasadas nas concepçôes de modelos digitais e conhecimento por simulação de Lévy (1987, 1993).

$\mathrm{Na}$ próxima seção, apresentamos esclarecimentos/entendimentos sobre as concepções de Lévy (1987, 1993) acerca de modelos digitais ou informáticos e sobre conhecimento por simulação. Em seguida, trazemos discussões

\footnotetext{
Doutorando em Educação em Ciências e Matemáticas pelo Programa de Pós-Graduação em Educação em Ciências e Matemáticas, do Instituto de Educação Matemática e Científica, da Universidade Federal do Pará. E-mail: rhominho.oliveira@hotmail.com. Agência Financiadora: CNPq. Doutora em Educação em Ciências e Matemáticas pela Universidade Federal do Pará, Professora Adjunta na Faculdade de Matemática, do Campus Universitário de Castanhal-Pará, da Universidade Federal do Pará. E-mail: robertabraga@ufpa.br

Doutor em Engenharia Elétrica pela Universidade Estadual de Campinas, Professor Titular da Universidade Federal do Pará, atualmente Coordenador do Campus Universitário de Salinópolis - Pará, da Universidade Federal do Pará. E-mail: adilson@ufpa.br
}

Instrumento: R. Est. Pesq. Educ., Juiz de Fora, v. 20, n. 2, jul./dez. 2018 
acerca da perspectiva de Modelagem Matemática assumida no trabalho, os sujeitos participantes e a abordagem metodológica. Posteriormente, apresentamos os dados, as discussões que emergiram desses dados, e as conclusōes.

\section{Modelos digitais ou INFORMÁticos E CONHECIMENTO POR SIMULAÇÃO}

Nesta seção, apresentamos o conceito de modelos digitais ou informáticos caracterizados nas obras de Lévy (1987, 1993). A primeira, A Máquina Universo, de 1987, e a segunda, As Tecnologias da Inteligência, de 1993. Nesses trabalhos, Lévy $(1987,1993)$ discorre sobre esses modelos como sendo frutos de programas simuladores, configurando o que denominou de aprendizagem por experiência (1987) / conhecimento por simulação (1993). Cabe ressaltar que os modelos discutidos por Lévy (1987) não são os mesmos abordados em discussóes acerca do modelo matemático oriundo do desenvolvimento de atividades de Modelagem Matemática.

Com o advento e desenvolvimento do computador e da informática, o homem passou a relacionar-se com o seu meio natural via interfaces digitais, podendo simular situaçóes e experiências sem entrar em contato direto com o que se está investigando. Desta forma, o poder da simulação surge como um importante instrumento utilizado em diversas áreas de atuação humana. Lévy (1987) exemplifica alguns usos, como:

As técnicas da informática musical permitem, em princípio, registrar, sintetizar e modificar, livremente, todos os elementos que levam à produção do som (p. 19). Os arquitetos, os urbanistas, os designers industriais ou os criadores de novas moléculas químicas examinam rapidamente, por meio de uma simples inspeção visual, as consequências das suas decisóes graças à simulação em três dimensóes (p. 21). Contrariamente ao mapa clássico, a imagem digitalizada convida o espectador a uma exploraçáo ativa, não somente por meio da interpretaçáo, mas também por intervençôes efetivas (LÉVY, 1987, p. 22).
A partir desse contexto e focando no ambiente educacional, tem-se também novas configurações no ambiente escolar, no qual Lévy (1987) destaca alguns pontos acerca de caminhos que apareceram para a aprendizagem dos alunos.

\footnotetext{
Graças aos programas de simulação, o estudante interage com modelos de processos complexos impossíveis de controlar na sua verdadeira dimensão. Experiências de física nuclear, evolução de modelos demográficos, hipóteses macroeconômicas são assim efetuadas sem perigo nem custos excessivos. Não se pode verdadeiramente falar de aprendizagem por experiência direta porque se trata de simulaçáo. Seria mais justo dizer que o estudante adquire um conhecimento prático da forma como os modelos digitais dos fenômenos se comportam quando ele modifica certos parâmetros. Ao familiarizar-se não somente com as reaçôes do processo modelizado, mas ainda com o princípio da simulação, o estudante faz a aprendizagem de uma das formas principais da experiência em um ambiente informatizado (LÉVY, 1987, p. 30).
}

$\mathrm{O}$ autor levanta alguns pontos que merecem destaque, por exemplo, quando se refere a "modelos" e à "aprendizagem por experiência". Em seu livro, Lévy (1987) atribui grande destaque às possibilidades que o desenvolvimento e avanço das tecnologias digitais trouxeram, de simular situaçóes, contextos e experiências. Como produto dessas simulaçôes, surgiram os modelos digitais ou informáticos.

Lévy (1993), para desenvolver a temática sobre a terceira tecnologia da inteligência, faz uso de comparaçóes com as tecnologias anteriores. Neste caso, ele o faz com a oralidade primária e a escrita, estabelecendo, dessa forma, distinçóes entre modelos obtidos a partir da escrita e os modelos obtidos por meio das simulaçóes virtuais. De acordo com Lévy (1993, p. 74):

\footnotetext{
Um modelo digital não é lido ou interpretado como um texto clássico, ele geralmente é explorado de forma interativa. Contrariamente à maioria das descriçōes funcionais sobre o papel ou aos modelos reduzidos analógicos, o modelo informático é essencialmente plástico, dinâmico, dotado de uma certa autonomia de ação e reação (LÉVY, 1993, p. 74).
} 
O modelo ao qual Lévy (1987) se refere se relaciona com representaçôes ou aproximaçóes de um determinado fenômeno real; dessa forma, o modelo teórico comporta-se de maneira estática e o digital ou informático, de maneira dinâmica. Diferentemente do modelo estático, próprio da escrita, entendido como um modelo teórico e considerado pela comunidade científica que o acolheu como uma verdade, o modelo digital ou informático não está comprometido em determinar verdades. Até porque a facilidade em realizar simulaçóes e manusear parâmetros permite ao pesquisador aprimorar seu modelo continuamente em um curto espaço de tempo. Essa facilidade acaba por apoiar o surgimento de verdades provisórias, modelos que podem ser aprimorados, modificados ou esquecidos na mesma velocidade com a qual foram construídos.

Ao falar dos modelos digitais ou informáticos, Lévy (1987) abre espaço para que se possa discutir sobre o que antecede esse modelo, ou seja, o processo que o gerou. Nesse cenário, destacamos as interfaces e a relação que o homem passou a ter nesses ambientes virtuais que acabam por produzir ao final uma síntese dessa interação. Essa síntese trata dos modelos digitais ou informáticos, enquanto que essa interação se refere ao conhecimento apreendido; esse tipo de apreensão de conhecimentos é cunhado pelo autor como aprendizagem por experiência.

Posteriormente, Lévy (1993) retoma esse conhecimento apreendido na interação do aluno com as interfaces, rebatizando-o como "conhecimento por simulaçâo". O autor reconhece os benefícios - ganho de tempo, diminuição de gastos financeiros, entre outros - que o desenvolvimento das tecnologias digitais e, consequentemente, dos programas simuladores trouxe para as atividades humanas. No entanto, seu destaque está no benefício cognitivo que essa ascensão tecnológica ensejou, já que, de acordo com este pensamento:

A manipulação dos parâmetros e a simulação de todas as circunstâncias possíveis dão ao usuário do programa uma espécie de intuição sobre as relaçóes de causa e efeito presentes no modelo. Ele adquire um conhecimento por simulaçáo do sistema modelado, que não se assemelha nem a um conhecimento teórico, nem a uma experiência prática, nem ao acúmulo de uma tradição oral (LÉVY, 1993, p. 75).

Lévy (1993), ao apresentar essa vertente de entendimento do que o processo de simulação pode garantir ao aprendizado do aluno, atribui a esses programas uma responsabilidade que ultrapassa o termo facilitador. Dessa forma, o aluno, ao interagir com ambientes frutos de simulações, tem a oportunidade de fazer previsóes, traçar estratégias, conjecturar possibilidades.

No exposto por Lévy $(1987,1993)$ evidencia-se, com o avanço das tecnologias digitais, que cada vez mais elas deixam de ser técnicas de suporte secundárias e passam a auxiliar o ser humano na construção de conhecimento, assumindo o papel de parceira e requerendo um espaço no processo de ensino e aprendizagem. Assim, ensejando conexóes com o processo de Modelagem Matemática, entendemos que o aluno pode, ao interagir com ambientes frutos de simulaçóes, fazer previsóes, estabelecer trajetórias e reconhecer caminhos infrutíferos que não os levariam a alcançar seus objetivos no contexto de uma atividade de Modelagem Matemática.

\section{Modelagem Matemática}

Sobre experiências com Modelagem Matemática, Araújo (2007, p. 17) destaca duas características: “a existência de uma multiplicidade de perspectivas de Modelagem Matemática e a transformação dessas perspectivas no contexto da Educação Matemática”. Para elucidarmos algumas dessas perspectivas, recorreremos à literatura de alguns autores.

D’Ambrosio (1996, p.11) afirma que a Modelagem Matemática se constitui em "um processo muito rico de encarar situaçôes reais”. Para Bassanezi (2011, p.17), a 
Modelagem Matemática "é um processo que alia teoria e prática". E Biembengut (2015, p.21) entende que a "Modelagem é o processo envolvido na elaboração de modelo de qualquer área do conhecimento". Nas perspectivas de D’Ambrosio (1996), Bassanezi (2011) e Biembengut (2015), a Modelagem Matemática é entendida como um processo para solucionar problemas extraídos de situações reais (externos à Matemática). Tem-se assim definida uma perspectiva de Modelagem Matemática que alia teoria e prática para/na solução de problemas reais.

Biembengut (2016) esclarece que o termo Modelagem Matemática, entendido como um processo de descrever, formular, modelar e resolver uma situaçãoproblema, aparece no início do século XX, nas literaturas do curso de Engenharia e de Ciências Econômicas. No cenário internacional, essa perspectiva de Modelagem Matemática é denominada de "Realística ou aplicada". Autores como Kaiser e Sriraman (2006) e Biembengut (2016) pontuam que, nessa perspectiva, os objetivos são pragmáticos, ou seja, reforça-se a ideia de solucionar problemas reais de outros contextos. Kaiser e Sriraman (2006) delimitam que os objetivos centrais dessa perspectiva são pragmáticos-utilitários na medida que propóem que se desenvolvam capacidades como: resolver problemas do mundo real, entender o mundo real e promover competências da Modelagem Matemática.

A atividade de Modelagem Matemática analisada neste trabalho foi desenvolvida no Laboratório Experimental de Modelagem Matemática, do Campus Universitário de Castanhal, da Universidade Federal do Pará (LEMM/CUNCAST/UFPA)1. A perspectiva de Modelagem Matemática assumida no LEMM converge com as concepções de Bassanezi (2011), que enxerga nas aplicaçóes o caminho para aproximar o aluno da Matemática. Sobre essas prerrogativas, Bassanezi (2011) apresenta a Modelagem Matemática como uma opção metodológica para a aplicação dos conteúdos matemáticos em outras áreas do conhecimento.
Segundo Bassanezi (2011), "pensar a unidade na multiplicidade" reflete o desafio da nova geração de professores e pesquisadores. E, nesse sentido, a Modelagem Matemática, como método de pesquisa ou estratégia de ensino, mostra-se eficaz, devido aos avanços obtidos por meio dela em áreas como Biologia, Física, Química, entre outras. Diante disso, Bassanezi (2011) entende esse método/estratégia como

(...) um processo dinâmico utilizado para a obtenção e validação de modelos matemáticos. É uma forma de abstração e generalização com a finalidade de previsão de tendências. A modelagem consiste, essencialmente, na arte de transformar situações da realidade em problemas matemáticos cujas soluçôes devem ser interpretadas na linguagem usual (BASSANEZI, 2011, p. 24).

A definição cunhada pelo autor remete também ao modelo matemático que, nesse caso, não caracteriza a realidade em sua totalidade, sendo apenas uma aproximação da situação-problema investigada. Ainda sobre o modelo, Bassanezi (2011) o descreve como

$$
\begin{aligned}
& \text { (...) a representaçáo de um objeto ou fato } \\
& \text { concreto; suas características predominantes são } \\
& \text { a estabilidade e a homogeneidade das variáveis. } \\
& \text { Tal representaçáo pode ser pictórica (um desenho, } \\
& \text { um esquema compartimental, um mapa etc.), } \\
& \text { conceitual (fórmula matemática) ou simbólica } \\
& \text { (BASSANEZI, 2011, p. 20). }
\end{aligned}
$$

Bassanezi (2011) pontua que, para a investigação de determinada situação ou problema real por meio da Modelagem Matemática, segue-se uma sequência de etapas, sendo elas: Experimentação, Abstração, Resolução, Validação e Modificação.

A escolha da temática ou problema a ser investigado vem antes de todo o processo. Sobre esse início, Bassanezi (2011) recomenda que as situaçóes escolhidas sejam abrangentes, dando margem ao surgimento de problemas em várias direçôes. Essa escolha deve ter a participação do aluno, pois ele precisa querer investigar o tema em questão. Mas a decisão final fica a cargo do professor, que assume o papel de 
conduzir o diálogo acerca da viabilização ou não da temática escolhida.

As etapas são as mesmas para a pesquisa e para o ensino. $\mathrm{O}$ que muda em ambos os contextos não são as etapas, e sim a intencionalidade de cada sujeito envolvido no processo. Por exemplo, como método de pesquisa, o matemático segue as etapas para chegar ao modelo mais próximo da situação-problema investigada. $\mathrm{O}$ modelo, nesse contexto, é o seu objetivo, não importando os caminhos e meios que ele utilizou para alcançá-lo. No ensino, o modelo também é objetivo do aluno; entretanto, esse objetivo está atrelado aos objetivos traçados pelo professor. Assim, as etapas que o aluno precisará para alcançar o seu objetivo se revelam para o professor como oportunidades de desenvolver conteúdos matemáticos e extramatemáticos.

\section{Abordagem metodológica}

Tradicionalmente, pesquisas em Educação Matemática são conduzidas por abordagens qualitativas. Malheiros (2004) comenta que "as pesquisas desenvolvidas na área de Educação, entre elas as de Educação Matemática, baseiam-se frequentemente pela abordagem qualitativa" (p. 57). Encontro também, no texto de Strauss e Corbin (2008), evidências que apontam essa popularização da abordagem qualitativa em vários campos de pesquisa.

Os métodos qualitativos de coleta e análise de dados ganharam popularidade com o passar dos anos [...]. Como uma metodologia e um conjunto de métodos, nossa técnica de pesquisa é usada por pessoas em campos de atuação como educação, enfermagem, administração de empresas e trabalho social, e também por psicólogos, arquitetos, especialistas em comunicação e antropólogos sociais (STRAUSS; CORBIN, 2008, p. 22).

Além desse viés histórico, observar nosso objetivo com este artigo e vinculá-lo ao objetivo dessa abordagem metodológica, que segundo Martins e Bicudo (2005, p.
23) "busca uma compreensão particular daquilo que estuda", ajudou-nos a perceber que a investigação à qual nos propusemos não permitia ser alcançada pelo viés de dados quantitativos, pois náo estamos preocupados com generalizaçôes, pelo contrário, almejamos um fenômeno específico, em que o uso de tecnologias digitais por alunos no desenvolvimento de atividades de Modelagem Matemática apresenta possibilidades de investigação e compreensão.

As pesquisas quantitativas requerem uma objetividade e uma precisão numérica que privilegiam a seleção de variáveis, experimentações, medições, observaçôes, entreoutros procedimentos. Diferentemente do que ocorre com a pesquisa qualitativa, que, segundo Martins e Bicudo (2005),

\section{(...) procura introduzir um rigor, que não o $\mathrm{da}$ precisão numérica, aos fenômenos que não são passíveis de serem estudados quantitativamente, tais como angústia, ansiedade, medo, alegria, cólera, amor, tristeza, solidáo etc. Esses fenômenos apresentam dimensóes pessoais e podem ser mais apropriadamente pesquisados na abordagem qualitativa (MARTINS; BICUDO, 2005 , p. 27, grifo nosso).}

Por isso, para alcançarmos o objetivo elencado, procuramos caminhos, métodos/estratégias/instrumentos que nos levassem a entender essas dimensóes pessoais, pois, no fenômeno que investigamos, alunos se relacionam com tecnologias digitais enquanto desenvolvem atividades de Modelagem Matemática, manifestando, nessa relação, interaçóes com o professor e com outros alunos.

Os dados que utilizamos neste trabalho foram oriundos do LEMM, produzidos em um curso com duração de 60 horas para alunos de graduação do curso de Licenciatura em Matemática. Foram registros documentais e registros em áudio e imagens que ilustraram o desenvolvimento de uma atividade de Modelagem Matemática. A análise dos dados aconteceu obedecendo a alguns momentos. Após organizar e selecionar os registros, detivemo-nos em situaçóes que 
pudessem contribuir para a investigação, implicando em escolhas e decisões baseadas no objetivo do estudo e no referencial teórico escolhido.

\section{Atividade “ResistênCia física HOMEM VERSUS MULHER"}

Nesta seção, descrevemos a atividade "Resistência físicaHomem versus Mulher", desenvolvida porduasalunas do curso de Licenciatura em Matemática no LEMM, que assumiram como objetivo verificar a relação entre a resistência física do homem e da mulher. $\mathrm{Na}$ descrição da atividade, fomos destacando em negrito situações em que houve o uso das tecnologias digitais ou situaçôes em que, a partir desse uso, as alunas tomaram decisóes em relaçáo às próximas etapas no desenvolvimento da atividade de Modelagem Matemática.
O início da investigação começou por pesquisas na internet, em que foi possível encontrar os cálculos referentes à Frequência Cardíaca (FC) e ao Índice de Massa Corpórea (IMC). Percebendo a necessidade de algumas mediçôes para a realização desses cálculos, as alunas viabilizaram no LEMM, com a participação dos outros alunos e da professora mediadora, a coleta de dados.

Para essa coleta, além da medição do peso e da altura, as alunas, no intuito de comparar o condicionamento físico do homem e da mulher, submeteram os participantes a um percurso de nove metros e meio, de ida e volta, que totalizava dezenove metros. Posteriormente, era registrado o tempo de realização desse percurso e a Frequência Cardíaca (FC) de cada participante. A partir dessa coleta de dados, as alunas montaram a Tabela 1 .

\begin{tabular}{|c|c|c|c|c|c|}
\hline VOLUNTÁRIO & PESO & ALTURA & F. C. & IMC & TEMPO \\
\hline Participante 01 & 58 & 1,61 & 36 & 22,3 & $0: 07: 35$ \\
\hline Participante 02 & 47,5 & 1,61 & 52 & 18,3 & 0: $07: 28$ \\
\hline Participante 03 & 42,5 & 1,49 & 48 & 19,1 & 0: 07: 53 \\
\hline Participante 04 & 49 & 1,56 & 44 & 20,1 & 0: 07: 50 \\
\hline Participante 05 & 50 & 1,61 & 72 & 19,2 & 0: 06: 90 \\
\hline Participante 06 & 70 & 1,58 & 36 & 28 & 0: 05: 97 \\
\hline Participante 07 & 57,5 & 1,55 & 68 & 23,9 & 0: $06: 72$ \\
\hline Participante 08 & 56 & 1,59 & 36 & 22,1 & 0: $07: 41$ \\
\hline Participante 09 & 79 & 1,54 & 68 & 27,3 & 0: $05: 47$ \\
\hline Participante 10 & 59 & 1,54 & 36 & 24,8 & $0: 05: 25$ \\
\hline Participante 11 & 71,5 & 1,6 & 60 & 27,9 & 0: 05: 78 \\
\hline Participante 12 & 61,5 & 1,7 & 48 & 21,2 & 0: $05: 78$ \\
\hline
\end{tabular}

Tabela 1 - Dados coletados pelas alunas

Fonte: Registros das alunas, 2014

Para a apresentação dos dados, as alunas com a qual puderam realizar testagens, verificando a recorreram a conteúdos matemáticos, como a Estatística, existência de correlação entre as variáveis Peso e Altura, e 
as varáveis FC e IMC. Dessa forma, as alunas iniciaram a testagem com as variáveis Peso e Altura, inserindo os dados na Planilha Eletrônica Excel, gerando, assim, o seguinte Gráfico de Dispersão:

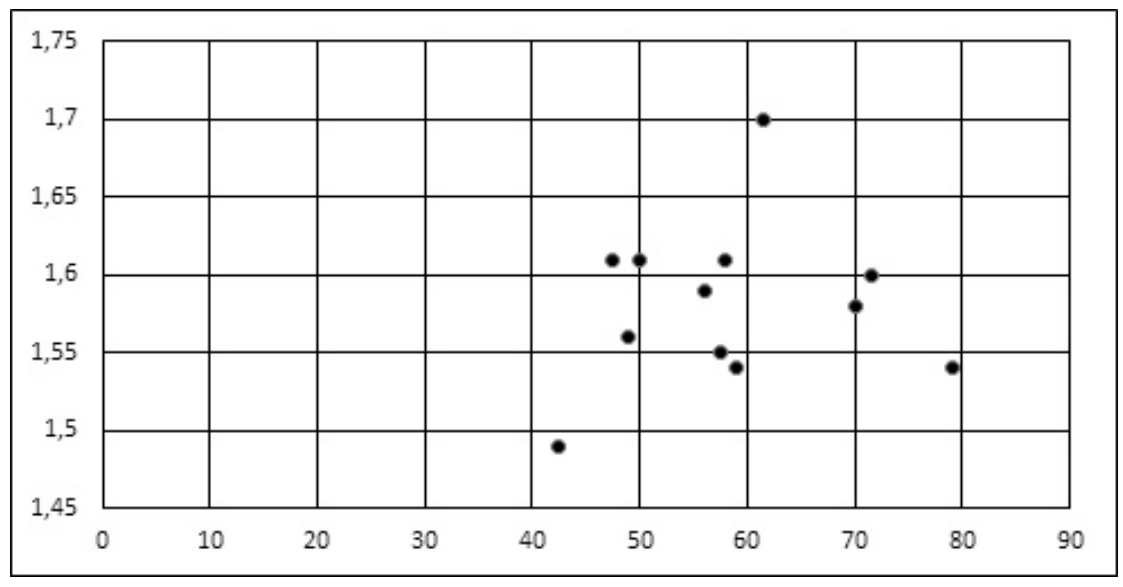

Gráfico 1 - Gráfico de Dispersão do Peso (x) versus Altura (y)

Fonte: Registros das alunas, 2014

Sobre o Gráfico 1, as alunas apontaram, pela disposição dos pontos, uma forma irregular, classificando-o como nuvem de pontos2. Em seguida, as alunas utilizaram o Coeficiente de Correlação de Pearson, o qual descreveram como sendo:

(...) uma medida do grau de relação linear entre duas variáveis quantitativas. Este coeficiente varia entre os valores -1 e 1 . O valor 0 (zero) significa que nâo há relação linear, o valor 1 indica uma relação linear perfeita e o valor -1 também indica uma relação linear perfeita, mas inversa, ou seja, quando uma das variáveis aumenta, a outra diminui. Quanto mais próximo estiver de 1 ou -1 , mais forte é a associação linear entre as duas variáveis (REGISTROS DAS ALUNAS, 2014).
E o apresentaram por:

$$
r=\frac{n \sum(x \cdot y)-\left(\sum x\right) \cdot\left(\sum y\right)}{\sqrt{n \sum x^{2}-\left(\sum x\right)^{2}} \cdot \sqrt{n \sum y^{2}-\left(\sum y\right)^{2}}}
$$

Como o cálculo do Coeficiente de Correlação de Pearson requeria várias operaçóes de resolução, as alunas compartimentalizaram essas operaçóes, com a finalidade de resolvê-las separadamente para depois reagrupálas. Essas resoluçôes foram realizadas com o auxílio da planilha eletrônica Excel e apresentadas na Tabela 2.

\begin{tabular}{|c|c|c|c|c|c|c|}
\hline$X$ & $y$ & $x^{*} y$ & $x^{2}$ & $y^{2}$ & $\left(\sum x\right)^{2}$ & $\left(\sum y\right)^{2}$ \\
\hline 58 & 1,61 & 93,38 & 3364 & 2,5921 & 519091,43 & 360,2404 \\
\hline 47,5 & 1,61 & 76,475 & 2256,25 & 2,5921 & & \\
\hline 42,5 & 1,49 & 63,325 & 1806,25 & 2,2201 & & \\
\hline 49 & 1,56 & 76,44 & 2401 & 2,4336 & & \\
\hline 50 & 1,61 & 80,5 & 2500 & 2,5921 & & \\
\hline 70 & 1,58 & 110,6 & 4900 & 2,4964 & & \\
\hline
\end{tabular}




\begin{tabular}{|c|c|c|c|c|l|l|}
\hline 57,5 & 1,55 & 89,125 & 3306,25 & 2,4025 & & \\
\hline 56 & 1,59 & 89,04 & 3136 & 2,5281 & & \\
\hline 79 & 1,54 & 121,66 & 6241 & 2,3716 & & \\
\hline 59 & 1,54 & 90,86 & 3481 & 2,3716 & & \\
\hline 71,5 & 1,6 & 114,4 & 5112,25 & 2,56 & & \\
\hline 61,5 & 1,7 & 104,55 & 3782,25 & 2,89 & & \\
\hline$\sum \mathrm{x}=$ & $\sum \mathrm{y}=$ & $\sum\left(\mathrm{x}^{*} \mathrm{y}\right)=$ & $\sum \mathrm{x}^{2}=$ & $\sum \mathrm{y}^{2}=$ & & \\
720,48 & 18,98 & 1110,355 & 42286,25 & 30,0502 & & \\
\hline
\end{tabular}

Tabela 2 - Resoluções das operações separadamente das variáveis Peso (x) e Altura (y)

Fonte: Registros das alunas, 2014

De posse das resoluçóes dos termos sinalizadas em cinza na Tabela 2, as alunas puderam reagrupar os resultados, substituindo-os em (1), incorrendo assim na resolução do coeficiente em um radical com radicando negativo, o que tornou inviável encontrar um resultado pertencente ao conjunto dos números reais. Tal situação fez com que as alunas concluíssem que, em se tratando das variáveis Peso e Altura, não existia correlação. Com essa conclusão, as alunas se voltaram para as variáveis FC e IMC, repetindo o mesmo processo de tratamento dos dados, primeiro os observando via recurso gráfico na planilha eletrônica Excel, como exposto no Gráfico 2.

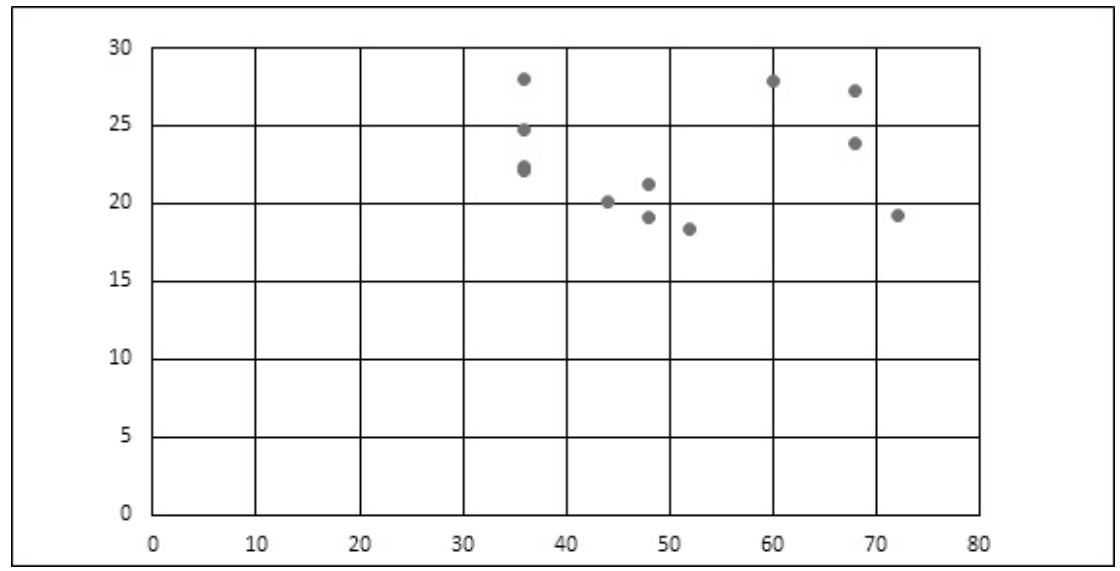

Gráfico 2 - Gráfico de Dispersão da F.C. (w) versus I. M. C. (z)

Fonte: Registros das alunas, 2014

Como ocorrido no Gráfico 1, as alunas constataram que os dados dessas variáveis também se encontravam dispersos, sem um contorno que sugerisse uma forma. Assim, novamente as alunas começaram a tratar os dados segundo o Coeficiente de Correlação de Pearson, resultando na Tabela 3. 


\begin{tabular}{|c|c|c|c|c|c|c|}
\hline $\mathbf{w}$ & $z$ & $\mathbf{w}^{*} \mathbf{z}$ & $w^{2}$ & $z^{2}$ & $\left(\sum w\right)^{2}$ & $\left(\sum z\right)^{2}$ \\
\hline 36 & 22,3 & 802,8 & 1296 & 497,29 & 364816 & 75185,64 \\
\hline 52 & 18,3 & 951,6 & 2704 & 334,89 & & \\
\hline 48 & 19,1 & 916,8 & 2304 & 364,81 & & \\
\hline 44 & 20,1 & 884,4 & 1936 & 404,01 & & \\
\hline 72 & 19,2 & 1382,4 & 5184 & 368,64 & & \\
\hline 36 & 28 & 1008 & 1296 & 784 & & \\
\hline 68 & 23,9 & 1625,2 & 4624 & 571,21 & & \\
\hline 36 & 22,1 & 795,6 & 1296 & 488,41 & & \\
\hline 68 & 27,3 & 1856,4 & 4624 & 745,29 & & \\
\hline 36 & 24,8 & 892,8 & 1296 & 615,04 & & \\
\hline 60 & 27,9 & 1674 & 3600 & 778,41 & & \\
\hline 48 & 21,2 & 1017,6 & 2304 & 449,44 & & \\
\hline$\sum_{604} w=$ & $\begin{array}{l}\sum z= \\
274,2\end{array}$ & $\begin{array}{c}\sum\left(w^{*} z\right)= \\
13807,6\end{array}$ & $\begin{array}{l}\sum w^{2}= \\
32464\end{array}$ & $\begin{array}{c}\sum z^{2}= \\
6401,44\end{array}$ & & \\
\hline
\end{tabular}

Tabela 3 - Resoluções das operações separadamente das variáveis F. C. (w) e I. M. C. (z)

Fonte: Registros das alunas, 2014

Inserindo as resoluçóes dos termos, em destaque cinza na Tabela 3, em (1), as alunas, pelo Coeficiente de Correlação de Pearson, obtiveram $r=0,011707269$. Esse resultado fez considerar que, pelo distanciamento das extremidades 1 e -1 e da proximidade com 0 , o resultado de $\mathrm{r}$ apontava uma fraca correlação entre as variáveis FC e IMC.

De modo geral, as alunas concluíram, embasadas nas investigações das variáveis Peso e Altura, FC e IMC, mediadas pela análise dos gráficos e das respostas obtidas com o Coeficiente de Correlação de Pearson, que não foi possível encontrar correlaçóes entre essas variáveis para esse grupo de participantes investigados, não podendo, assim, alcançar o objetivo determinado inicialmente, que era de relacionar a resistência física do homem e da mulher, apontando qual gênero era mais resistente fisicamente.

\section{MODElOS Digitais OU INFORMÁTICOS NO DESENVOLVIMENTO DA ATIVIDADE "RESISTÊNCIA FÍSICA HOMEM VERSUS MULHER"}

Como mencionado na seção 4, durante a descrição da atividade, fomos destacando em negrito algumas situaçôes. Essas marcaçôes possibilitaram estabelecer um foco, levando em conta nosso objetivo, sobre os dados de que dispúnhamos. Assim, nesta seção, apresentamos as análises desses destaques, segundo as concepçóes que elucidamos sobre modelos digitais e conhecimento por simulação de Lévy $(1987,1993)$ e sobre a perspectiva de Modelagem Matemática de Bassanezi (2011).

As alunas queriam comparar quem tinha maior resistência física, o homem ou a mulher. Por isso a escolha 
das variáveis Peso e Altura para o cálculo do IMC e a escolha do percurso para verificar a FC dos participantes após uma atividade física. Para o tratamento e a análise desses dados, as alunas utilizaram a planilha eletrônica Excel e o Coeficiente de Correlação de Pearson. Ambos os recursos ajudaram as alunas a entender que as variáveis identificadas e mensuradas, da forma como foram tratadas, não resultaram em alternativas para que se continuasse a investigação da atividade.

Em relação ao processo de Modelagem Matemática, as alunas não desenvolveram todas as etapas. Houve, assim, a escolha do tema, "Resistência física Homem versus Mulher", e a escolha, a partir de pesquisas na internet, dos cálculos do IMC e da FC. Essas escolhas subsidiaram a determinação das variáveis e da coleta de dados.

A coleta de dados, segundo Bassanezi (2011), pode ser efetuada de várias formas, dentre elas, a feita através de entrevistas e de pesquisas executadas com os métodos de amostragem aleatória. Nesse caso, que é próximo da forma de coleta de dados realizada pelas alunas nessa atividade, o autor destaca como sendo de fundamental importância a organização de um questionário eficiente e a utilização de alguns conceitos básicos de Estatística.

As alunas não utilizaram questionários, entretanto, recorreram a uma amostragem de participantes do gênero masculino e feminino que tornou possível a coleta e o posterior estudo estatístico dos dados via planilha eletrônica Excel. Assim, tem-se, nessas primeiras açôes das alunas, características próximas das descritas por Bassanezi (2011) acerca da primeira etapa do processo de Modelagem Matemática, a Experimentação.

Com essa coleta e a realização dos cálculos do IMC e da FC, as alunas perceberam que as variáveis elencadas não apresentavam nenhuma relação de dependência. Desta forma, foi esse entendimento, de que as variáveis elencadas eram independentes, que levou as alunas a optarem pelo uso da planilha eletrônica Excel e o Coeficiente de Correlação de Pearson como recursos para o trato das variáveis elencadas.

Nesse sentido, a professora mediadora argumenta que, mesmo trazendo dados de variáveis independentes para o plano cartesiano, as alunas não tinham a intenção de encontrar uma função para o comportamento desses dados. Desta forma, o Gráfico de Dispersão serviu, segundo as ações das alunas e segundo as consideraçóes da professora mediadora, como meio para se refletir/ traçar caminhos cabíveis para as análises dos dados coletados. Bassanezi (2011) corrobora essa ação das alunas afirmando que "(...) A disposição dos dados em um sistema cartesiano e um bom ajuste dos seus valores facilitará a visualização do fenômeno em estudo, propiciando tentativas de propostas de problemas, conjecturas ou leis de formação" (p. 43).

Sobre o ajuste citado por Bassanezi (2011), as alunas, após a visualização dos dados, partiram para um Ajuste Linear, com o cálculo do Coeficiente de Correlação de Pearson. A escolha desse tipo de ajuste para os dados em questão mostra-se inadequada, pois, ao visualizar esses dados no Gráfico de Dispersão, as alunas tinham condições de inferir que não haveria correlação entre as variáveis. Porém, essas foram as escolhas das alunas, não cabendo discutir aqui qual seria o ajuste mais adequado.

Neste contexto, essas açóes que envolveram o tratamento dos dados coletados a partir dos Gráficos de Dispersão e do Ajuste Linear caracterizam momentos próximos aos descritos na segunda etapa do processo de Modelagem Matemática por Bassanezi (2011): Abstração. Como já mencionado, as alunas terminam a investigação dessa atividade nessa etapa por não enxergarem, nas variáveis trabalhadas, condiçooes viáveis que pudessem determinar o alcance do objetivo estabelecido incialmente, que era de relacionar a resistência física do homem e da mulher e, consequentemente, apontar quem tinha maior ou menor resistência. 
Sobre a interação das alunas com a interface da planilha, Lévy (1993, p. 123) considera que "a manipulação dos parâmetros e a simulação de todas as circunstâncias possíveis dão ao usuário do programa uma espécie de intuição sobre as relações de causa e efeito presentes no modelo". No desenvolvimento da atividade "Resistência física Homem versus Mulher", percebemos que as alunas adquiriram uma intuição sobre o fenômeno investigado na medida em que iam controlando e manipulando as variáveis Peso/Altura e FC/IMC. Essa intuição se mostra no controle das alunas sobre a temática investigada, que possibilitou fazer previsóes e tomar decisões com relação ao desenvolvimento das próximas etapas do processo de Modelagem Matemática.

Nesse cenário, as alunas adquiriram conhecimentos sobre a temática investigada, na medida em que visualmente, pelos gráficos de dispersão, e algebricamente, pelo cálculo do CoeficientedeCorrelação de Pearson, elas perceberam que, para aquele grupo de sujeitos, para aquelas variáveis, a escolha do ajuste linear não era viável. Entendemos esse conhecimento acerca do comportamento das variáveis elencadas e da fraca correlação entre elas quando submetidas a um ajuste linear (conhecimentos específicos da temática investigada) como fruto da interação das alunas com a interface da planilha eletrônica Excel (simulação), configurando assim um conhecimento por simulação da situação modelada (LÉVY, 1987, 1993).

\section{CONSIDERAÇÓES FINAIS}

Retomando o objetivo que nos propusemos neste artigo, que foi investigar implicações surgidas no uso da planilha eletrônica Excel para o desenvolvimento da atividade de Modelagem Matemática, traçamos algumas consideraçóes.

Alguns momentos analisados na atividade "Resistência física Homem versus Mulher", desenvolvida no LEMM, atendem a esse objetivo, considerando que os modelos digitais ou informáticos criados/ manipulados pelas alunas na planilha eletrônica Excel foram importantes para tomada de decisão acerca dos próximos passos a serem traçados no processo de Modelagem Matemática.

Nessa atividade, as alunas puderam verificar visualmente que as variáveis eram independentes e, assim, posteriormente, confirmar essa fraca correlação pelo cálculo do Coeficiente de Correlação de Pearson. Percebemos também uma interação das alunas com a interface da planilha eletrônica Excel, que possibilitou um domínio de conhecimento acerca da temática investigada tal qual defende Lévy (1993), quando trata do "conhecimento por simulação".

Desta forma, acreditamos que o uso da planilha eletrônica Excel possibilitou a configuração de ambientes de simulação e investigação pertinentes ao desenvolvimento de atividades de Modelagem Matemática, pois permitiu às alunas e à professora mediadora dominarem especificidades do fenômeno investigado que incidiram na escolha de caminhos dentro do processo de Modelagem Matemática.

\section{ARISING IMPLICATIONS FROM THE USE OF DIGITAL TECHNOLOGIES IN THE DEVELOPMENT OF MATHEMATICAL MODELING ACTIVITIES}

\section{Abstract}

The aim of this paper is to investigate arising implications in the Excel spreadsheet in order to develop a mathematical modeling activity. The study method was qualitative and the data was collected at the Experimental Laboratory of Mathematical Modeling at the Federal University of Pará, Castanhal Campus (LEMM/ 
CUNCAST/UFPA). The results indicate that the use of digital technologies influences student's decisions, which affect the development of the next steps of mathematical modeling process.

Keywords: Implications. Digital technologies. Mathematical modeling activities.

\section{IMPLICACIONES SURGIDAS EN EL USO DE TECNOLOGÍAS DIGITALES EN EL DESARROLLO DE ACTIVIDADES DE MODELADO MATEMÁTICO}

\section{Resumen}

El objetivo de este artículo es investigar las implicaciones surgidas en el uso de la hoja de cálculo Excel para el desarrollo de una actividad de Modelado Matemático. El método de estudio fue el cualitativo y los datos fueron recolectados en el Laboratorio Experimental de Modelado Matemático, del Campus Universitario de Castanhal, de la Universidad Federal de Pará (LEMM / CUNCAST / UFPA). Los resultados indican que el uso de tecnologías digitales repercute en la toma de decisiones de los alumnos, impactando en el desarrollo de las próximas etapas del proceso de Modelado Matemático.

Palavras clave: Implicaciones. Tecnologías digitales. Actividades de modelado matemático.

\section{Notas}

O LEMM é fruto de um projeto da segunda autora (coordenadora/ professora), que tem como objetivo fomentar a iniciação científica com alunos do curso de Licenciatura Plena em Matemática no desenvolvimento de atividades de Modelagem Matemática. O LEMM conta com diversos instrumentos e equipamentos para o Ensino de Matemática: decibelímetro; equipamento de revolução de sólidos; conjuntos laboratoriais que possibilitam diversos experimentos em áreas como Matemática, Física, Química, Biologia; computadores conectados à internet com softwares para recebimento e tratamento de dados; lousa interativa, entre outros. Essa nomenclatura é própria da investigação de diagramas de dispersão (MARTINS; PONTE, 2011).

\section{REFERÊNCIAS}

ARAÚJO, J. de L. Cálculo, tecnologias e modelagem matemática: as discussóes dos alunos. Tese (Doutorado em Educação Matemática) - Instituto de Geociências e Ciências Exatas (IGCE), Universidade Estadual Paulista (UNESP), Rio Claro, 2002.

BASSANEZI, Rodney Carlos. Ensino-aprendizagem com modelagem matemática. 3.ed. São Paulo: Contexto, 2011.

BIEMBENGUT, M. S. Modelagem na educação matemática e na ciência. São Paulo: Editora Livraria da Física, 2016.

Modelagem matemática no ensino fundamental. Blumenau: Edifurb, 2015.

D'AMBROSIO, Ubiratan. Educaçâo matemática: da teoria à prática. 14. ed. Campinas, SP: Papirus, 1996.

DINIZ, L. do N. O papel das tecnologias da informaçâa $e$ comunicação nos projetos de modelagem matemática. Dissertação (Mestrado em Educação Matemática)-Instituto de Geociências e Ciências Exatas, Universidade Estadual Paulista (UNESP), Rio Claro, 2007.

KAISER, G.; SRIRAMAN, B. A global survey of international perspectives on modelling in mathematics education. The International Journal on Mathematics Education. v. 38, n. 3, 2006.

LÉVY, P. As tecnologias da inteligência: o futuro do pensamento na era da informática. São Paulo: Editora 34, 1993.

LÉVY, P. A máquina universo: criação, cognição e cultura informática. Lisboa: Instituto Piaget, 1987.

MALHEIROS, A. P. S. A produção matemática dos alunos em ambiente de modelagem. Dissertaçáo (Mestrado em Educação Matemática) - Instituto de Geociências e Ciências Exatas, Universidade Estadual Paulista, Rio Claro, 2004.

MARTINS, J.; BICUDO, M. A. V. A pesquisa qualitativa em psicologia: fundamentos e recursos básicos. 5. ed. São Paulo: Centauro, 2005. 
MARTINS, M. E. G.; PONTE, J. P. Organização $e$ tratamento de dados. Lisboa: Ministério da Educação 2011.

STRAUSS, A.; CORBIN, J. Pesquisa qualitativa: técnicas e procedimentos para o desenvolvimento de teoria fundamentada. 2. ed. Porto Alegre: Artmed, 2008.

Enviado em 20 de maio de 2018. Aprovado em 14 de agosto de 2018. 